\title{
Aspects on a Digitalized Industrialization Process: Are There Challenges to Overcome?
}

\author{
Edris SAFAVI ${ }^{\mathrm{a}, \mathrm{b}}$ and Paraskeva WLAZLAK ${ }^{\mathrm{b}}$ and Kerstin JOHANSEN ${ }^{\mathrm{b}, 1}$ \\ ${ }^{a}$ Department of Flight mechanics and weapon integration, SAAB Aeronautics, \\ 58254 Linköping Sweden \\ ${ }^{\mathrm{b}}$ Department of Product development, Production and Design, Jönköping University, \\ 55111 Jönköping, Sweden
}

\begin{abstract}
Increased possibilities to utilize digital tools in the industrialization process where a product move from conceptualization toward mass production is challenged with how to develop resilience in such process. Several digital tools such as $\mathrm{CAD}$, CAE, Production flow analysis, assembly analysis, and off-line programming of robots and $\mathrm{CNC}$ machines are commonly used in industry for both product development and production. There are also many good initiatives such as computational multidisciplinary design optimization or design automation in the aircraft industry to integrate such digital tools and increase the efficiency of the generating and distributing of information. However to maximize the benefit of digitalization, a fully digitalized platform is required where all parties including the product development team, manufacturing resources, suppliers, and even customers can contribute efficiently. Although establishing such a digitilized platform seems very promising, it confronts many challenges in a large firm. Hence, this paper, based on a theoretical outlook related to industrial observations, will explore challenges and opportunities related to the digitalization of product development and the manufacturing process.
\end{abstract}

Keywords. Digitalization, Product development, Manufacturing industry

\section{Introduction}

Product life cycle (PLC) encompasses the time from product introduction to the market until it is removed from the shelves and not possible to buy any longer. It has four stages - introduction, growth, maturity, and decline [1-3]. While some products may stay in a prolonged maturity state, all products eventually are phased out due to e.g., market saturation, increased competition, and decreased demand. However, many high-tech products are characterized by short PLCs. According to prior research [4], the products where designers spend more time on engineering and development have lengthier PLCs. These products, however, require continuous adjustment and updates with changing customer requirements [4], which increases the need for the ability to manage different variants with flexibility both in the design as well as manufacturing process [5].

Development of a product with a long-life cycle e.g., aircraft; consist of a large number of interconnected activities, which are normally partitioned into several phases such as Design, Production, Operation, and Decommissioning [4],[6]. The design phase comprises market research, requirements specification, conception, design management, 
overall design (including design for $\mathrm{X}$ ), and design of components. Production includes selection and development of production technologies, production planning and management, supply of materials and components, manufacturing, assembly, testing, and quality assurance. Operation includes the scheduling and management of the use of aircraft and its crew within a fleet; the maintenance and repair tasks and resources; and the logistics support tasks and resources. Decommissioning consists of safe disposal and recycling of components and/or materials.

The current practice is to consider each phase of the lifecycle separately managed by different teams of specialists, often from different organizations, with limited interactions between them [4] or that the different organizations are coordinating all communication in a network [7]. Based on observations in the studied company, there is no central lifecycle management team charged with coordinating all activities from product idea to its disposal and recycling. Moreover, each phase of the lifecycle is normally supported by stand-alone computer systems, such as computer-aided design (CAD), computer-aided engineering (CAE), computer-aided manufacturing (CAM), enterprise resource planning (ERP), and various production and logistic schedulers, which are rarely fully compatible with each other and never integrated into a single lifecycle system. This contributes to key lifecycle activities with no connections between them, and thus delays the useful flow of information, particularly feedback from manufacturing, assembly, operation, maintenance, and support to design. Consequently, designers have no real-time access to data on failure analysis, which is necessary to understand the relationship between failures and design decisions. Nevertheless, the safety record of the aircraft industry is excellent. That is why manufacturing companies that develop products with long life cycles strive to improve management of the complexities while maintaining or improving current levels of safety. This example that has been observed, links to the challenge of linking different tools to support transdisciplinary interaction across different phases in a design phase [8] as well as between different phases in the PLC and keep an excellent safety record in the aircraft industry.

With an increase of digitalization during production, it becomes easy to gather information during the production phase and provide immediate input to what is going on with a product in operations [9-10]. From a production system perspective, it is common to use simulation software e.g., production flow analysis, assembly analysis, and off-line programming of robots and CNC machines [11]. However, companies that move towards full digitalization and automation of engineering processes that are necessary for integrated product and production development face various challenges [10]. That is why; this paper explores challenges and opportunities related to the digitalization of product development and manufacturing process. The industrialization process is a part of the production phase and it is associated with all the activities that are necessary to prepare a product for production [12], [13]. The success of an industrialization process is affected by how well product and production development are integrated [14].

\section{Product development and digitalization reform}

Manufacturing industries in general and the aerospace industry particularly are trying to improve product profitability by streamlining the product development process (PDP). One trend is that companies implement novel PDPs for more innovative products with 
less development time. However, this is a challenge for industries dealing with complex products that consist of thousands of parts, design routines, design evaluation points, where product development takes more than 10 years. Hence, digitalization seems like one of the most important solutions at hand. However, the digitalization of a complex PDP in a large company is challenging and not straightforward. Furthermore, digitalization is a general word that can be interpreted differently in various contexts. Nowadays almost all companies benefit from digitalization to some degree. In this study, fully digitalized PDP is referred to as a process where all parties such as design engineers, manufacturing teams, and even external parties can contribute. A fully digitalized platform includes many software tools that need to be managed appropriately. This requires many interdisciplinary and transdisciplinary collaboration within the organization that may not be easily achieved [8],[15]. It has been proven beneficial to integrate manufacturing knowledge, suppliers, and customers early into a design process [16-21]. This helps to decrease the probability of problems later in the development process. Typically, PDPs used in manufacturing industries consist of linear or transitional phases and routines, as well as decentralized information flow. In this approach, the product information increases and transfers to later stages as the product develops. However, it is not so efficient to involve more parties in the product development with less interruption. Therefore, a data-centric approach is proposed to evolve more information (external parties) into the product development process efficiently. It has been proven that many advanced PDP techniques such as multidisciplinary design optimization (MDO), collaborative multidisciplinary design optimization (CMDO), and even Interdisciplinary design (ID) are more efficient using data-centric architecture [22-23]. In this approach, information from each discipline is collected in a database, which is accessible by other disciplines in the PDP. This is where Product Lifecycle Management (PLM) and Product Data Management (PDM) tools could be very helpful to track the information flow and facilitate the accessibility of such knowledge. The data-centric approach is used to facilitate communications among design teams, share information and manage complexity [24]. The fully digitalized PDP in this paper is referred to as a data-centric product development approach [24-26].

\section{Smart manufacturing}

The goal of smart manufacturing or its synonym "Industry 4.0 " is to automate manufacturing processes, were fully integrated and collaborative manufacturing systems rapidly can respond to meet the demand and conditions. Frank et al. [9] explore the pattern about how emerging technologies related to "Industry 4.0" are implemented in the industry up until now, but also exploring the lack of understanding of how to implement these technologies. These emerging technologies, in combination with the increased digitalization, challenge the IT infrastructure [27], and if implemented they need to be managed concerning efficiency, productivity, and flexibility [28]. To manage Machine-to-Machine (M2M) communication and other Internet of Things (IoT) solutions, the traditional manufacturing environment is changing from material flow to information flow, which emphasizes the role of data management in the success of smart manufacturing [29]. However, elements related to organization and work procedures are not a primary concern in early industrial development phases [30], which indicates that a transition towards smart manufacturing must include more than just technical implementation. 


\section{Methodology}

This study is based on observations of a research project at SAAB Aeronautics that was about the digital transformation of the PDP, from now on referred to as Transform Project. The project aimed at enhancing and speeding up the PDP using state of an art digitalization approach. The subject of observation was the Transform Project and its set up both technically and administratively. One of the authors of this paper was involved in the Transform Project as a domain expert and carried out the observations of the challenges and opportunities related to the transformation to fully digitalized PDP. The project team consisted of 2 conceptual engineers, 6 domain experts, and one project manager acting as a data architecture. The team used the PLM system to share data. The observations were carried from early brainstorming sessions and later throughout the project. Observations were carried out during weekly project meetings, daily e-mails exchanged between the project manager and the team members. Furthermore, observations took place during four training sessions, where team members got familiar with the software tools. During observations, notes were taken with a focus on challenges and opportunities during the digital transformation.

In addition to the observations, informal semi-structured interviews with four experienced professionals involved in digital transformation at SAAB Aeronautics were carried out [31]. The interviewees were two domain experts, a line manager, and the research coordinator. The informal interviews included questions about the informants' experience with the digitalization process, and what were the general challenges and opportunities involved in such a process.

The data analysis followed the steps prescribed by Miles et al., namely data condensation, data display, and conclusion drawing/ verification [34]. To triangulate the collected data, evidence from different key respondents and through different methods was collected. Through interviews and observations, challenges and opportunities with digital transformation were brought forward. To strengthen the internal validity, enfolding of literature during the analysis was carried out [35-36]. Contrasting literature to empirical findings was crucial for strengthening the external validity of this study.

\section{Empirical material}

\subsection{Digitalization concept in the product development process}

The observed challenges for the product development team were gathering/generating design information and its efficient sharing. It was observed that the team preferred to change the traditional sequential data access approach, see Figure 1, to a data-centric approach. The data-centric approach was proven to be efficient at SAAB. In this approach, the generated data was accessible upon all product generations to all design parties through a centralized data center. Concerning this approach, several challenges and possibilities were observed, see Figure 2.

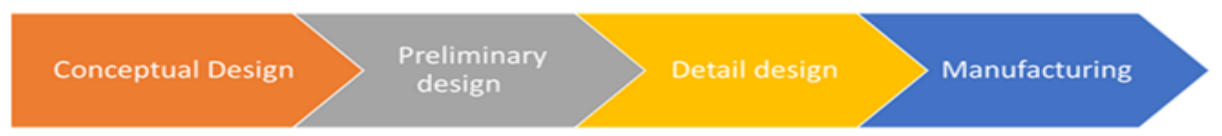

Figure 1. Management of data in Decentralized PDP (conventional) 


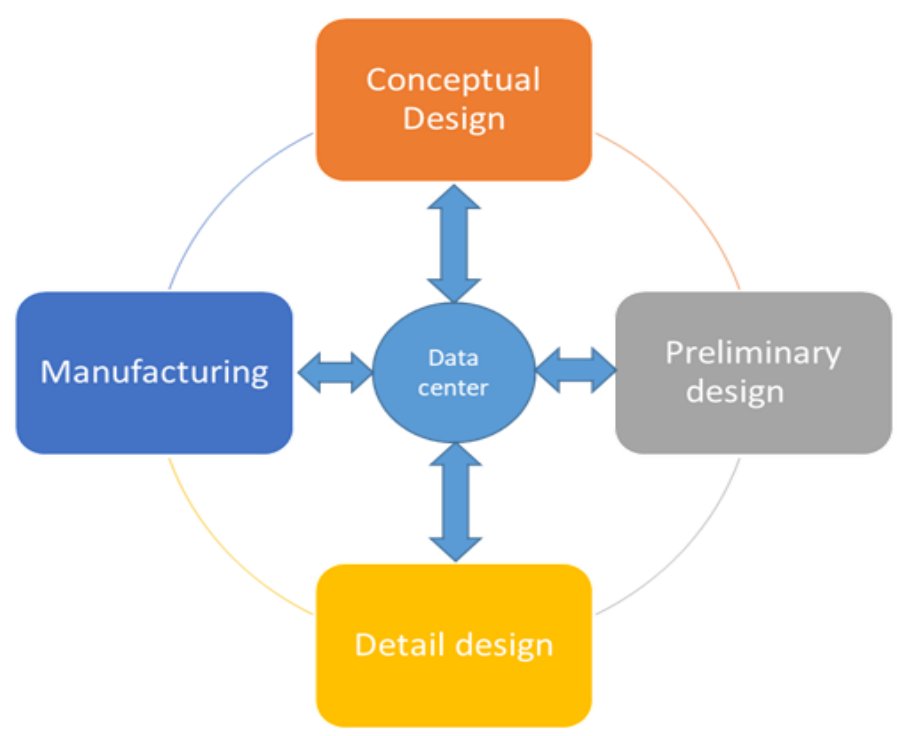

Figure 2. Management of data in Centralized PDP (future approach)

\subsection{Project organization}

Observation during the Transform Project showed tremendous organizational challenges where the interdisciplinary and transdisciplinary links between departments, divisions, and even product development groups were missing. SAAB used a decentralized organizational chart with many hierarchies. The project team as an issue when implementing a data-centric approach because various decisions had to be shared fast with all concerned employees pointed this. This was also confirmed during the interviews with the experienced professionals involved in digitalization transformation at SAAB. To avoid this organizational challenge, the project manager was acting as a data center. The role of the project manager was to share all managerial information among the team using daily email and weekly meetings. However, the observation showed that at the beginning of the project the team members had difficulties understanding each other due to a lack of knowledge about each other's domains. To increase integration the project manager set up weekly meetings where each domain expert provided knowledge about the domain, potentials, and limitations. Observations revealed that during one early meeting some domain experts complained about the unbalanced workload between their routine job and their involvement in the Transform Project. As a result, the project manager had to discuss this issue with all line managers requesting allocation of more time of the domain experts needed in the Transform Project.

\subsection{IT infrastructure}

Observation showed that the team faced many IT difficulties from hardware to software and cyber securities. Some of the project team members were not equipped with proper 
hardware capable of running the software efficiently. The team was faced with a cybersecurity problem early in the Transform Project, as it was not allowed to install new software on the existing IT infrastructure. This was a very important challenge that took weeks and hundreds of person-hours to solve. The team had to run a dedicated IT system locally to avoid the IT regulatory of the company. This provided many challenges for the team to overcome various IT problems. Another issue that had raised during the interview is the reliability of the new software and its generated results. The interviewee mentioned that it took about a year to decide if the used software in the Transform project was reliable enough to start with or not. Observations showed that the lack of knowledge of the experts about the new software was yet another challenge. As previously stated, the team manager set up training sessions for the project team members so that they could get familiar with the new tools.

Table 1. Summary of the findings during observations and interviews

\begin{tabular}{|c|c|c|}
\hline Aspect & Observations & Interviews \\
\hline $\begin{array}{l}\text { Digitalization } \\
\text { concept }\end{array}$ & $\begin{array}{l}\text { Moving from sequential } \\
\text { PDP to data-centric PDP }\end{array}$ & $\begin{array}{l}\text { Digitalization was necessary for } \\
\text { information generation and } \\
\text { distribution }\end{array}$ \\
\hline $\begin{array}{l}\text { Project } \\
\text { organization }\end{array}$ & $\begin{array}{l}\text { - Agile team for proof of } \\
\text { concept was created }\end{array}$ & $\begin{array}{l}\text { Organizational changes were } \\
\text { needed to remove decision-making } \\
\text { bottlenecks } \\
\text { Lack of experts equipped with } \\
\text { knowledge of digitalization was a } \\
\text { concern }\end{array}$ \\
\hline $\begin{array}{l}\text { IT } \\
\text { infrastructure }\end{array}$ & $\begin{array}{l}\text { Hardware update was } \\
\text { required } \\
\text { A software update was } \\
\text { required } \\
\text { - } \quad \text { A dedicated IT system } \\
\text { was required } \\
\text { Training of the team } \\
\text { member was required }\end{array}$ & $\begin{array}{l}\text { A software update was required to } \\
\text { support a data-centric approach } \\
\text { - } \quad \text { Cybersecurity was a challenge } \\
\text { Reliability of the results was a } \\
\text { challenge } \\
\text { - } \quad \begin{array}{l}\text { Education and training of the } \\
\text { engineers was a challenge }\end{array}\end{array}$ \\
\hline
\end{tabular}

\section{Analysis and discussion}

The findings indicated that moving from semi-digitized PDP to fully digitalized PDP was not an easy task. During the digital transformation organizational challenges related to missing interdisciplinary and transdisciplinary links between departments, divisions, or product development groups could be encountered. The findings showed that oldfashioned organizational charts with many hierarchical levels could challenge the digital transformation aiming at centralization of the information flow and open-access information. Based on the findings, this study emphasizes that a centralized information flow platform may be promising for fully digitized PDP. The findings showed that applying fully digitalized PDP required specialized expertise. To achieve the required level of expertise a remedy was in-house training of employees, which was less costly and more efficient compared to hiring new employees. The lack of expertise in digital product architecture and integration is also stressed in the prior research [8].

One problem that might occur about the digital transformation is the employees' motivation. Introducing changes in organizations is not an easy task and employees could be reluctant and hesitant to the changes [43]. The related organizational challenge was the unbalanced level of digitalization for various departments, which needed to be taken 
into consideration when planning for digital transformation. This finding was in line [38] stressing the need for a review and update of work procedures as well as organizational development. Moreover, the findings showed that involving suppliers and customers in the digital transformation is important for companies that want to maintain relationships with external parties.

The findings showed that establishing a stable IT infrastructure to support digitalized PDP and manufacturing was not an easy task. Moving towards more advanced digital tools required machines with high computational capabilities and new hardware. Apart from the high cost, the hardware systems required training, support, maintenance, and more importantly continuous updating over a timeframe.

The conventional software was used as stand-alone and dedicated to a specific domain. However, the digital transformation required higher collaboration from other domain experts and therefore the architecture of the information flow had also to be changed. Fortunately, there are many advanced approaches such as MDO, PLM, and $\mathrm{PDM}$, to integrate domain expert's knowledge into a knowledge-sharing platform [44]. However, the findings showed that there was a lack of expertise to efficiently deal with the new software, not just on the users' side (domain experts and engineers) but also on the support and services side.

Nowadays there are many commercial computational digital tools e.g., from MS excel to Matlab, CAD, and CAE which are used in the PDP [45]. However, the findings of this study showed that the integration of these tools to a centralized digital platform was challenging. Although there are some commercial integrator tools available such as ModeFrontier [39], Heeds [40], 3Dexperience [41], etc., the study showed that dealing with such tools was not an easy task in the industry. This was mainly because of the lack of extensive knowledge available in the industry.

Companies have experience with digital tools and are familiar with which tools are suitable for what tasks, what are the gains and the limitation and more importantly how reliable these tools are [46]. This is very valuable knowledge that companies gain over the years. The findings of this study showed that knowledge about the reliability of the tools and the creditability of the results was accumulated during many design iterations and validations. Therefore, changing the tools or the PDP in a well-established company with many years of experience was perceived as risky in terms of losing such reliability and creditability. The findings showed that there was a need to verify and validate the results of the new digital tools based on real use case data over time. In a fully digitalized PDP with many tools involved, this evaluation and validation was not an easy task as uncertainty in one tool may propagate to the others. Hence, companies that embark on a digital transformation journey need to have the capabilities to manage uncertainties and establish plans and methods for reviewing the design and outcomes of the tools.

\section{Conclusions and outlook}

The findings of this study are summarized in Table 1 and show that digital transformation brings several organizational and technical challenges.

To conclude, this study stresses that it is important to establish a clear vision for digitalization before the transformation process commences. A well-defined strategy to reach the vision for digitalization and new metrics that will capture progress towards that vision is needed. The vision has been defined under Industry 4.0 where front-end technologies consist of four dimensions: Smart Manufacturing, Smart Products, Smart 
Supply Chain, and Smart Working [9]. To achieve this, it is required to employ four base elements as the Internet of Things, cloud services, big data, and analytics. This study puts forward that a digital vision needs to consider companies' existing core competencies and strengths.

Digital transformation requires not only selecting the right technology but also implementing this technology in a company's core. However, a company cannot get the full benefits of digitalization until reaching digital maturity [42]. Digital maturity is achieved when integration of the operations and human capital of a company is done successfully into digital processes and vice versa [42]. Digitally mature companies understand the importance of technology adoption. If an employee cannot benefit from the features and advantages conferred by digitalization, companies will not see a positive return on investment [30]. That is why, as this study points out it is essential to establish effective training for the employees to adopt the new digital tools.

Cybersecurity and reliability analysis is another important factor that digitally mature companies need to consider [27]. Digitalization without proper planning of the security and reliability of a system can attract malicious users who aim to infiltrate weaknesses within the systems for their gain, referred to as cybersecurity attacks.

This study also points out that there is a lack of a digital system architect who can have a holistic view and understand the different phases of the PDP process including data generation and dataflow. An architect should have a good understanding of a company's digital environment and the associated limitations and potentials. The role of an architect could be to help the domain expert to develop digital models that could efficiently be integrated into a company's centralized digital platform. This study points out a gap between the company's need for expertise, including a deep understanding of architecture technologies both on domain and integration levels, and the specialists at the work market. The identified gap put higher demands on the universities to develop specialists who are knowledgeable in managing this transdisciplinary challenge.

This study discusses plenty of challenges that could potentially reduce the importance of the benefits that companies could achieve by undertaking digital transformation using the right tools and processes. For example, by achieving a higher degree of integration of product development and manufacturing through digitalization companies have opportunities to smooth their industrialization process. Better integration will provide the opportunity for companies to deal with interdependencies of product engineers' and manufacturing engineers' tasks as early as possible in the development process and avoid potential engineering changes later in the PDP. It is important to detect the need for engineering changes as early as possible because product changes become more expensive and harder to manage the later they are implemented [13]. The opportunities for companies with digitalization are summarized below:

- Companies can keep or even increase their competitive advantage.

- Companies' management team can collect valuable information about assets, processes, products, and customers.

- Companies can retain market share less costly.

- Companies can gain higher profitability when more efficient processes are implemented.

- Companies can improve PDP, production efficiency, machine uptime, performance, and even consumed materials. 


\section{Acknowledgment}

The authors acknowledge the SPARK research environment at Jönköping university funded by the KK-foundation in Sweden and the program Recruitment that has made it possible to have a fellow adjunct from the industry to the academia.

\section{References}

[1] C.R. Anderson and C.P. Zeithmal, Stage of the Product Life Cycle, Business Strategy, and Business Performance, Academy of Management Journal, 1984, Vol. 27 No. 1, pp. 5-24.

[2] G. Day, The Product Life Cycle: Analysis and Applications Issues. J of Marketing, 1981, Vol 45(4), pp. 60-67.

[3] D.R. Rink and J.E. Swan, Product life cycle research: A literature review, Journal of Business Research, 1979, Vol. 7, (3), pp. 219-242.

[4] M. Price, D. Soban, C. Mullen, J. Butterfield and A. Murphy, A novel method to enable tradeoffs across the whole product life of an aircraft using value-driven design, Journal of Aerospace Operations, 2012, Vol.1(4), pp. 359-375.

[5] A. Oke, A framework for analyzing manufacturing flexibility, Int. J. of Operations \& Production Management, 2005, Vol. 25, No. 10, pp. 973-996.

[6] S. Jones and G. A. Zsidisin., Performance implications of product life cycle extension: The case of the A-10 aircraft. Journal of Business Logistics, 2008, Vol. 29, pp. 189-214.

[7] K. Johansen, M. Comstock, M. Winroth, Coordination in collaborative manufacturing mega-networks: A case study, In. J. of Engineering and Technology Management, 2005, Vol. 22, pp. 226-244.

[8] M. Goudswaard, B. Hicks, L. Newnes, An Appraisal and Classification of the Transdisciplinarity of Existing Design Tools, Advances in Transdisciplinary Engineering, 2020, Vol. 12, pp. 50-59.

[9] N. Wognum, C. Bil, F. Elgh, M. Peruzzini, J. Stjepandić and W.J.C. Verhagen, Transdisciplinary engineering research challenges, Advances in Transdisciplinary Engineering, 2018, Vol. 7, pp. 753762.

[10] A. Schumacher and W. Sihn, A Strategy Guidance Model to Realize Industrial Digitalization in Production Companies. J of Management and Production Engineering Review, 2020, Vol. 11(3), pp. 14-25.

[11] K. Thoben, S. Wiesner and T. Wuest, Industrie 4.0 and Smart Manufacturing - A Review of Research Issues and Application Examples, Int Journal of Automation Technology, 2017, Vol. 11. pp. 4-19.

[12] Le Dain M., Calvi, R., \& Cheriti S., Measuring supplier performance in collaborative design: Proposition of a framework. Journal of R\&D Management. 41. 2010.

[13] Wlazlak P., Eriksson Y., Johansson G., \& Ahlin P., Visual representations for communication in geographically distributed new product development projects, J of Eng Design, 30:8-9, 2019, pp.385403.

[14] P. Wlazlak, K. Säfsten and P. Hilletofth, Original equipment manufacturer (OEM)-supplier integration to prepare for production ramp-up, Journal of Manufacturing Technology Management, 2019, Vol. 30, No. 2, pp. 506-530.

[15] O. Khan, T. Stolte, A. Creazza and Z.N. Lee Hansen, Integrating product design into the supply chain, Cogent Engineering, 2016, Vol. 3, Issue 1, 1210478

[16] K.E. Gruner, C. Homburg, Does customer interaction enhance new product success?, In. J. of Business Research, 2000, Vol 49 (1), pp. 1-14.

[17] X Huang, G.N. Soutar, A. Brown, New product development processes in small and medium-sized enterprises: Some Australian evidence, J. of Small Business Management, 2000, Vol 40 (1), pp. 27-42.

[18] D.W. LaBahn, Early supplier involvement in customer new product development: A contingency model of component supplier intentions, Journal of Business Research, 2000, Vol. 47 (3), pp. 173-190.

[19] M. Swink, Threats to new product manufacturability and the effects of development team integration processes, Journal of Operations Management, 1999, Vol. 17 (6), pp. 691-709.

[20] S.P. Leo Kumar, Knowledge-based expert system in manufacturing planning: state-of-the-art review, International Journal of Production Research, 2019, Vol. 57 (15-16), pp. 4766-4790.

[21] M. El Souri, J. Gao, C. Simmonds, Integrating manufacturing knowledge with the design process to improve quality in the aerospace industry, Procedia CIRP, 2019, Vol 84, pp. 374-379.

[22] E. Safavi, Collaborative Multidisciplinary Design Optimization for Conceptual Design of Complex Products, PhD. dissertation, Linköping University, 2016, https://doi.org/10.3384/diss.diva-131792. 
[23] S.J. Culley, B.J. Hicks, T.C. McAloon, T.J. Howard and Y. Reich, Dimensions of objectives in interdisciplinary product development projects, DS 68-2: Proceedings of the 18th Int Conference on Engineering Design (ICED 11), Impacting Society through Engineering Design, Vol. 2: Design Theory and Research Methodology, Lyngby/Copenhagen, Denmark, 15.-19.08.2011, pp 256-265.

[24] D. Kohr, M. Ahmad, B. Alkan, M. Chinnathai, L. Budde, D. Vera, T. Friedli and R. Harrison, Proposing a Holistic Framework for the Assessment and Management of Manufacturing Complexity through Data-centric and Human-centric Approaches, Proceedings of the 3rd International Conference on Complexity, Future Information Systems and Risk, Madeira/Portugal, 2018, pp. 86-93.

[25] D. Zahay, A. Griffin, E. Fredericks, Sources, uses, and forms of data in the new product development process, Industrial Marketing Management, 2004, Vol. 33, Issue 7, pp. 657-666.

[26] W.D. Li and Z.M. Qiu, State-of-the-art technologies and methodologies for collaborative product development systems, International Journal of Production Research, 2006, Vol. 44:13, pp. 2525-2559.

[27] R. Ande, B. Adebisi, M. Hammoudeh, J. Saleem, Internet of Things: Evolution and Technologies from a Security Perspective, Journal of Sustainable Cities and Society, 2019, Vol 54, pp.10-16.

[28] E. Oztemel and E. Gursev, Literature review of Industry 4.0 and related technologies, Journal of Intelligent Manufacturing, 2020, Vol. 31, pp. 127-182.

[29] K. Schwab, The Fourth Industrial Revolution. Crown Publishing Group, New York, 2017.

[30] J. Wiklund, T. Baker and D. Shepherd, The age-effect of financial indicators as buffers against the liability of newness, In. J. of Business Venturing, Vol. 25(4), 2010, pp. 423-437.

[31] SAAB, SAAB Technologies, 2021, Accessed: 14.03.2021. [Online]. Available: www.SAAB.com

[32] FCAS, Future-Combat-Air-System, Accessed 14.03.21 [Online] available https://www.airbus.com/newsroom/stories/Future-Combat-Air-System-Owning-the-sky-with-theNext-Generation-Weapons-System.html

[33] Open CPS, Accessed 14.03.2021. [Online] available https://opencps.eu/

[34] M.B. Miles, A.M. Huberman and J. Saldana, Qualitative analysis: a methods sourcebook. $3^{\text {rd }} \mathrm{ed}$, SAGE, Los Angeles, 2014.

[35] M.K. Eisenhardt, Building theories from case study research. The Academy of Management Review, 1989, Vol 14 (4), pp. 532-550.

[36] C. Voss, N. Tsikriktsis and M. Frohlich, Case research in operations management. International Journal of Operations and Production Management, 2002, Vol 22 (2), pp. 195-219.

[37] S. Jamshed, Qualitative research method-interviewing and observation, J. Basic Clin Pharm., 2014, Vol 5(4), pp. 87-88.

[38] J. Wiklund, T. Baker and D. Shepherd, The age-effect of financial indicators as buffers against the liability of newness. Journal of Business Venturing, Vol. 25(4), 2010, pp. 423-437.

[39] Modefrontier, the Multidisciplinary design optimization software, accessed 14.03.2021 [online] available https://www.esteco.com/modefrontier.

[40] Heeds, design exploration and optimization software, accessed 14.03.2021, [online] available https://www.redcedartech.com/index.php/solutions/heeds-software

[41] 3d experience, accessed 14.03.2021, [online] available https://www.3ds.com/3dexperience.

[42] I.V. Aslanova and A.I., Kulichkina, Digital Maturity: Definition and Model, In Proceedings of 2nd International Scientific and Practical Conference "Modern Management Trends and the Digital Economy: from Regional Development to Global Economic Growth" (MTDE 2020), Yekaterinburg, Russia, 2020.

[43] P. Mugge, H. Abbu, T.L. Michaelis, A. Kwiatkowski and G. Gudergan, Patterns of Digitization: A Practical Guide to Digital Transformation, Research-Technology Management, 2020, Vol. 63:2, 2735, DOI: $10.1080 / 08956308.2020 .1707003$.

[44] J. Gao, A.Y. Nee, An overview of manufacturing knowledge sharing in the product development process. Proceedings of the Institution of Mechanical Engineers, Part B: Journal of Engineering Manufacture. 2018, Vol. 232(13), pp. 2253-2263, doi:10.1177/0954405418759375.

[45] T.J. Marion and S.K. Fixson, The Transformation of the Innovation Process: How Digital Tools are Changing Work, Collaboration, and Organizations in New Product Development, Journal of Product Innovation Management, 2021, Vol. 38.1, pp. 192-215.

[46] M. Eek, On credibility assessment in aircraft system simulation, $\mathrm{PhD}$ Thesis, Linköping University Electronic Press, 2016. 